Article

\title{
Reconsidering Journalist Safety Training
}

\author{
Marte Høiby ${ }^{1, *}$ and Mariateresa Garrido V. ${ }^{2}$ \\ ${ }^{1}$ Department of Journalism and Media Studies, Oslo Metropolitan University, 0130 Oslo, Norway; \\ E-Mail:mahoib@oslomet.no \\ 2 International Law Department, University for Peace, 138-6100 San Jose, Costa Rica; E-Mail: mgarrido@upeace.org \\ * Corresponding author
}

Submitted: 30 September 2019 | Accepted: 9 January 2020 | Published: 25 February 2020

\begin{abstract}
Safety training courses and manuals are designed to provide journalists with guidance to assess and mitigate risk. In this article, we ask whether content of such training and guidance is informed by actual threats and risks relevant to journalists working in the field. Departing from our own previous research about threats and dangers faced by journalists working in conflict zones or covering dangerous beats, and a review of the literature addressing the issue of safety manuals for journalists, we evaluate the content of five safety-training documents. Of these, two are descriptions of internationally-focused safety courses, two are safety manuals produced for a national audience, and one is a handbook focusing specifically on safety for women reporters in the Arab region. The purpose is to identify various aspects of safety addressed in training and manuals offered to locally and internationally-deployed journalists-and illuminate how they may differ in focus and approach. Through a comparison of the content of the selected manuals and course descriptions, we conclude that these trainings and manuals to some extent address specific variations in context, but that detailed attention towards gender differences in risk and other personal characteristics are not given equivalent weight. The international training focuses excessively on physical environment issues (such as those of a 'hostile environment'), while the manuals with national or regional focus are practice-oriented and largely take a journalistic point of departure. We argue that training and manuals can benefit from considering both these aspects for risk assessment, but recommend that addressing journalistic practice and personal resources is fundamental to all journalist safety training since it is at the personal, practical, and media organisational levels that the mitigation encouraged by these trainings can happen.
\end{abstract}

\section{Keywords}

conflict reporting; hostile environment training; journalist safety; safety training; war journalism

\section{Issue}

This article is part of the issue "Rethinking Safety of Journalists" edited by Kristin Skare Orgeret (Oslo Metropolitan University, Norway) and William Tayeebwa (University of Makerere, Uganda).

(C) 2020 by the authors; licensee Cogitatio (Lisbon, Portugal). This article is licensed under a Creative Commons Attribution 4.0 International License (CC BY).

\section{Introduction}

Despite awareness and a growing concern about the threats and dangers faced by journalists covering wars from the battlefield, dangerous assignments related to politics, corruption, and human rights issues are the ones for which most journalists have lost their lives (Committee to Protect Journalists, 2019). Foreign war correspondents have been scrutinized in (Western) research, but less attention has been paid to the nu- merous local journalists covering conflict in their home environment. At the same time, globalisation, technological advancement, and new media development is changing the scenery, posing new threats to journalists' safety (Høiby, 2016, 2019a, 2019b; Høiby \& Ottosen, 2018). Globalisation and new technology are also blurring the division between local and distant assignments. Investigative projects increasingly happen through collaborative consortiums cutting through geographical borders, cultures, and contexts. Consequently, risks and 
threats in one area transit to another in which they may not have appeared before. Another such often-neglected part of journalists' safety is legal risks. It is usually underestimated how understanding the legal environment in which journalists are going to operate, prepares them to better defend themselves and to avoid legal persecution (Garrido V., 2017a, 2017b). These are all issues that demand more attention from a journalist's safety perspective. That said, our approach to journalist safety is not to place the responsibility onto media organisations and journalists alone. Yet, it is important to keep in mind that training and manuals are constructed to secure individual safety; they do not aim to challenge the structures of any society with a long-term objective. Therefore, in this article we treat them as efforts to mitigate a problem that is rooted in society, and must be considered in the light of the weaknesses of our social institutions and structures.

Through previous research, the authors of this article have investigated threats and dangers faced by journalists in countries across the world (Uganda, Tunisia, Nigeria, Nicaragua, Venezuela, the Philippines, Nepal, and Norway), and found deficiencies in training manuals to tackle safety issues previously mentioned. This article analyses five safety manuals and training content descriptions provided by two major international trainers (AKE and HEAT) and three local ones, from the Philippines, Venezuela, and the Arab region (the latter focusing specifically on gender issues). These are purposely selected, and the aim of this article is merely to discuss and present some aspects of the potential discrepancy in content embraced in training and advice to journalists. The sample does not provide a comprehensive picture of journalist safety training on the market but indicates the focus of some training manuals and courses available to and used by journalists and trainers in these regions.

Research suggests that safety issues depend on context in geography and culture, but also journalistic practice and type of assignment (Garrido V., Høiby, \& Mitra, 2019). Among the manuals and content descriptions we have analysed, the 'international' ones appear to have taken geography and environment well into consideration but put less emphasis on the type of story and information involved in the assignment. The 'local' training manuals, on the other hand, appear to place the journalistic project and individual characteristics at the centre of attention. The reason for this may be that the producers of local safety training and/or manuals were journalists themselves, while the producers of the so-called hostile environment training were not. And it may not be surprising that the manual offered to women journalists was produced by a woman and published by an association of women journalists.

Therefore, our research questions for this article are:

RQ1: To what extent, and how, does our sample of training manuals and training content descriptions address the safety issues facing local and international journalists today?
RQ2: How do the manuals and content descriptions in our selection overlap or differ from each other in content and/or focus?

RQ3: How are issues related to contextual variations, legal issues and digital issues addressed?

Throughout the article, we argue that training should take into consideration local contexts (such as regime type, state cohesiveness, and social institutions), globalization, technological advancement, legal issues, and differences in journalistic practices, ethics, and media organizational routines. We conclude in this article that while journalists may have much to gain from insights to the battlefield, training designed to meet the safety requirements for journalists may have something to learn from the journalism profession. Gender differences in threats and dangers appear critically absent but it is imperative to address them in both.

\section{Theory on Journalist Safety Training and Manuals}

In Risky Assignments: Sexing "Security" in Hostile Environment Reporting (2007), author Carrie A. Rentschler discusses the constructions of 'risk' and 'security' in post-9/11 training manuals for non-embedded journalists preparing for assignments in so-called hostile environments. Rentschler analyses how what she terms "training documents" (i.e., manuals) "translate ideas about risk and reporting, through the language of choice, into sexed and gendered prescriptive cues about securing professional comportment in the field" (2007, p. 257).

Among the documents that were analysed in the study was a 105-page text titled Practical Guide for Journalists published by Reporters without Borders (RSF) in 2002, aimed at preparing journalists for war reporting. Rentschler notes that like other "texts of its kind," the guide "draws its interpretive framework from the linguistic coffers of risk management" and focuses heavily on health and life insurance, first aid procedures, the avoidance of minefields and recognition of weaponry (Rentschler, 2007, p. 257).

The author's main criticism of the documents analysed, however, is not on the training contents per se, but the masculinised and securitised form of presentation in training documents. She emphasises the "culture of risk awareness" addressed by the General Secretary of the International Federation of Journalists' 2003 training manual titled Live News: A Survival Guide for Journalists (cited in Rentschler, 2007):

There is an interesting story here to tell of the current post-feminist, neo-liberal context in which some of the dangers of journalism are being defined and managed through client relationships between the news industry and the private security industryrelationships that become especially clear when 
articulated through training manuals. (Rentschler, 2007, p. 258)

While Rentschler points to the skewed presentation of gender in some of these manuals, such as the male heroism and female victimisation exhibited in their use of photos, the manuals also fail to address the risks women journalists face in the field. She concludes that "security training by-and-large acts as if sex and gender matter little to the practice of journalism, despite its sexed and gendered frameworks for portraying risk and safety" (Rentschler, 2007, p. 274):

And feminists continue to remind us that war and other hostilities are always gendered and raced realities, as are the calls for security that seek to address them. As neoliberal tools that re-inscribe sexual and gendered power relations onto the bodies of reporters and news photographers, this analysis warns us that discourses of security are never simply about how to be safe in an increasingly threatening world. (Rentschler, 2007, p. 275)

In the same fashion, a more recent study investigating the effectiveness and user satisfaction of journalist safety training (here defined as hostile environment training or hazardous training), points to a significant gender gap in overall satisfaction between women and men as the most imperative finding (Slaughter, Newman, Brummel, \& Drevo, 2018). Through a survey of 247 journalists, men $(n=131)$ reported higher satisfaction than women $(n=116)$ on all four measures included in the study, which were: 1) overall satisfaction; 2) whether they would recommend the training to others; 3) satisfaction with the trainers' knowledge; and 4) the content's sensitivity and accuracy concerning gender and diversity threats (Slaughter et. al, 2018, p. 53).

Thus, an idea that should not be underrated in this discussion is that the private security industry is a growing (and very profitable) business that profits more from continuing to fuel such aspects of securitisation, heroism, and masculinisation than from addressing the realities and needs that can be met with expertise that already exists within the media's own industry. We therefore suggest that what appears as a shortcoming of sensitivity towards gender, is in fact rather a symptom of the field from which their competence derives - the security industryshaped by military and highly masculinised approaches (see e.g., Barkawi, Dandeker, Wells-Petry, \& Kier, 1999).

The first problem in relation to safety training is not necessarily the nature of the training but the fact that very few receive any form of safety training or equipment at all (Høiby \& Ottosen, 2015, 2016). But as safety training is increasingly offered to journalists at least in the larger companies, the type of training they receive is important to underscore. It is reasonable to believe that training designed by larger companies offering courses to diverse fields of occupations, such as NGO workers, profiled business officers travelling to danger zones and so on, would lack necessary insight to the occupational aspects of safety for journalists and the very issues that increasingly put members of the press at extra risk.

\subsection{Findings from Previous Research: The Threats Journalists Face}

Because the aim of training is to avoid the materialization of threats, it is necessary to describe the different types of threats that journalists face. However, we must clarify that it is not possible to present a complete and exhaustive list of threats because they change and adapt to social realities. In addition, threats depend on the environment in which journalists operate, and vary from country to country. In most cases, the threats journalists experience is the result of their reporting; hence, for the purposes of this article, we consider as threats any attempt seeking to diminish journalists' possibilities to perform their job.

In the 20th century, threats were physical, which explains why most of the safety training focused on this aspect. Physical threats have not changed much, and they include murder, kidnapping, forced disappearance, arbitrary arrests, prosecutions, and deportation (United Nations General Assembly, 2012). They continue to exist, and their occurrence depends on other factors like political affiliation (e.g., El Salvador), social unrest (e.g., Nicaragua), so-called "drug wars" (e.g., Philippines), complex humanitarian crisis (e.g., Venezuela), or postconflict situations (e.g., Nepal).

Threats and dangers faced by journalists conform to a spectrum of different causes and motives (Høiby, 2019b). They can be targeted attacks on singular journalists, in retaliation for published work or in an attempt of hindering disclosure of illicit activity; or, they can target an entire media outlet to send a message and try to diminish critical coverage. They can be accumulated by continuous and/or long-lasting exposure to the physical field where events related to war and conflict occur-such as elections, demonstrations, poor resilience to natural disasters, areas with poor access to health care, etc. In general, the potentially deteriorating safety conditions for journalists relate to an increasingly globalised world and conglomerated media.

In the 21st century, we are observing that digital threats coexist with physical threats. They are increasing all over the world and they depend on the local context too (Henrichsen, Betz, \& Lisosky, 2015; UNESCO, 2018). The most common digital threats are related to mass surveillance, vulnerabilities in the system for data storage and publication, and complex digital attacks that involve limitations to access digital platforms and data mining, and that produce a breach in the privacy of the journalist, the media, and the audience (UNESCO, 2018). For example, in Venezuela, journalists consider social media hacking, Distributed Denial of Service (DDoS) attacks against their internet-based platforms, verbal at- 
tacks, and even the approval of regulations that seek to control the creation and dissemination of digital content as serious threats. However, in some cases, journalists do not take appropriate measures because they do not know the digital tools they can use or because they do not have access to them (Garrido V., 2017c). For that reason, we also assume that training should entail a focus on digital threats to provide journalists with the necessary tools for protection.

In addition to those scenarios, there is an increasing tendency to harass women in social media through "stalking, hate speech via graphics or text, cyber mobbing, revenge porn, unwanted sexual attention and sexual coercion" (MacKinnon, Hickok, Bar, \& Lim, 2014, p. 172). The threats and harassment against women are documented to be of a more sexualised character (Chen et al., 2018). In some cases, threats extend to their relatives, especially their children or spouses (Garrido V., 2017c). Nonetheless, these forms of threats have also changed, and UNESCO indicates that women journalists also face public shaming, hate speech, cyber-bullying, trolling, doxing, and cyber-stalking (UNESCO, 2018, p. 156). The consequences of the threats are innumerable, but in highly hostile environments, it is possible to observe an increase in self-censorship. In Venezuela, journalists considered this practice necessary to avoid the closure of the media; to increase the possibilities to acquire the permissions needed to buy newsprint, new equipment, and spare parts; and to diminish the possibilities to receive verbal attacks (Garrido V., 2017c). Therefore, we also assume that training that does not consider gender is inadequate.

Moreover, legal threats are a reality in several parts of the world. Legal mechanisms that were designed to protect journalists can be used to legally harass journalists, and to impose several limitations to the exercise of journalism. Ambiguous regulations on the plurality of the media, control and even the protection of other's rights, allow authorities to make arbitrary interpretations of the law, and apply them to threaten media outlets who are critical or who oppose government's policies (Garrido V., 2017c). For this reason, we also considered references to legal mechanisms as a criterion to assess the selected training manuals.

\section{Method}

Although we, the authors of this article, train both students and practising journalists in safety issues ourselves, we have investigated other sources to evaluate the content of training courses and manuals that are available on the market. Information about courses is in general hard to acquire. One of the reasons that explains the lack of information is the competition among trainers. To disclose detailed information about the content can affect their business model because many of them profit from making a personalized offer and from having direct communication with interested people. Another reason that may explain why information is not available is the concerns about leaking information that can potentially jeopardise the security of participants or insurance aspects. In consequence, we chose and assessed a small sample of training course descriptions and safety manuals that are digitally accessible to a larger audience and that we knew have been used in each region. While this sample is limited in providing a clear insight into the content of training, especially so for the ones we only have a course description, they do indicate something about the general focus.

Altogether, the sample consists of two course descriptions, two safety guidelines and one safety handbook. We consider the three latter documents to be sufficient as study objects for this purpose, while the two first-the course descriptions-only provide a very limited glimpse of what their training (which usually last between four and seven days) actually contains but that allows us to make the comparison between international and local training. Therefore, it is with great caution that we comment on the potential fulfilment or neglects of these. It is important to underscore that the true contribution of this study is however not limited to the analysis of these manuals and course descriptions in isolation, but the evaluation of the full sample in relation to our previous analysis of threats and risks journalists face in the field.

The sample content descriptions and training manuals that we have analysed are as follows:

- AKE Working in Hostile Regions (UK): crossnational focus (UK, Canada, Australia, and Thailand). Used and developed by the organization for their training courses;

- Hostile Environment Awareness Training (HEAT; Norway): international focus. Used and developed by the Norwegian Refugee Council (NRC);

- What if...? Safety Handbook for Women Journalists (Arab region): gender focus. Used by the International Association of Women in Radio \& Television (IAWRT) and developed by the journalist Abeer Saady;

- Philippine Journalist Safety Guide-A Handbook for Filipino Journalists (Philippines): local focus. Used by the National Union of Journalists of the Philippines and developed by the organization with the assistance of Internews;

- Practical Guideline for the Protection of Journalists (Venezuela): local focus. Used by the local organization Espacio Público and developed by its journalists.

For the analysis, we considered who produced them and when they were produced or published, what their main purpose seems to be and its target audience (and whom they are accessible to). In relation to the content, we evaluated what safety issues they addressed and how. Thus, we focused on the identification of the types of threats they considered, the solutions offered, and references to the context in which journalists operate and to their per- 
sonal characteristics. On this last point, we paid attention to issues related to gender, ethnicity, or other personal characteristics, as well as to aspects of journalism (the story, assignment, media ethics, etc.), legal issues, and digital development. Then, we used that information from each training course description and safety manuals to make a comparison and answer the main research questions of this article.

\subsection{Sample Description}

\subsubsection{AKE Working in Hostile Regions Training}

The organization advertises this training in its website as a course "designed to assist individuals, teams and organisations to prepare for and manage risk whilst living and working in, complex and sometimes hostile environments" (AKE International, 2019). The organisation indicates that through the use of a "mixture of lectures, discussion groups, workshops and practical simulations and exercises" participants would be prepared to work in hostile environments, identify physical threats, develop techniques to mitigate risk, and provide medical assistance if needed, and to function effectively for long periods of time in these environments (AKE International, 2019).

A special report on "Journalism in Hostile Regions" published by the organization indicated that they also provide " $24 / 7$ crisis response and in-country support services" (AKE International, 2017). In that report, they specified that they have trained journalists in Afghanistan, China, Egypt, Mexico, Sudan, South Sudan, and Ukraine (AKE International, 2017). It is noticeable that in the same report the organization stated that "together with bespoke reports prepared by regional experts from AKE's Intelligence department, journalists are provided with tailored risk analysis and mitigation strategies" (AKE International, 2017).

The group appeals to the media industry and the general media user population with the argument that now anyone using a smartphone can be taken for a journalist, and that this assumingly puts 'everyone' at greater risk.

In their course description, there is no mentioning of gender issues or other individual characteristics, nor to journalistic tasks or threats. However, from the mentioned report, it is possible to observe that the AKE training does focus on regional and national differences in context and demonstrates high awareness of the variety in the environment that can potentially affect the journalists. Awareness of the situation for foreign journalists in China and the inclusion of attention to travel documents and allowances indicate that they do specialise on contextual factors for journalists in designated areas. This focus appears somewhat tailored to journalists operating internationally and travelling to specific areas about which AKE can offer training. Attention to legal issues (beyond the retrieval of legal documents and allowances for access) is not indicated, and digital threats are not specifically addressed (AKE International, 2017).

\subsubsection{The NRC's HEAT Course}

A course offered to humanitarian workers, media personnel and private sector companies whose staff travel to or live in high-risk environments for longer periods is the NRC's Hostile Environment Awareness Training (HEAT). HEAT is "a form of high fidelity stress exposure training that combines theory with high-stress and highly realistic simulation training" (NRC, 2019). The organization indicates that, in this five-day training, participants gain the knowledge and skills needed to manage real threats.

Their teaching methodology includes the use of "a mix of advanced theoretical and practical sessions of simulated exercises" (NRC, 2019). The content description does not necessarily reveal everything included in the training, and it is possible that they hold other elements not mentioned in the description. What is outlined is that, at the end of the training, participants should have "a firm grasp of" managing basic first aid and psychological first aid, personal safety and security, safety and security mindset, communications equipment, capture and captivity, behaviour under fire, threats in the field, fire safety, basic negotiation skills, understanding how to build individual situational awareness in high risk environments, and unexploded ordnance, and improvised explosive device (IED) threats (NRC, 2019).

The description does not reveal specific attention to legal or digital threats, concerns related to ethnicity or gender, or other individual characteristics, nor to journalistic tasks or threats.

\subsubsection{The IAWRT Safety Manual}

IAWRT published the Safety Handbook for Women Journalists in 2017 with the support of the Norwegian Union of Journalists and UNESCO. The handbook is written by Abeer Saady and it is available and free to download at IAWRT's website.

The publication seeks to provide to female journalists working in conflict areas a "concrete and practical handbook, with advice and recommendations on security and safety" (Saady, 2017, p. 1). The content is structured around three main areas: physical safety, digital safety, and psychosocial safety-emphasizing those situations in which gender plays a determining role.

It starts by encouraging female journalists to make risk assessments, and utilise simple questions to initiate and guide the process, such as, what are the possible threats? When and where can they happen? Who can be perpetrators? To answer those questions, it requests journalists to consider their personal circumstances in relation to the environment in which the journalists work (or will work). It considers issues related to religion, race, nationality, education, language, clothing, equipment, political views, type of work (undercover, independent, embedded, etc.).

Many of the safety tips relate to physical safety; however, it includes recommendations on digital safety to 
avoid surveillance and theft of both devices and data. This manual also provides advice to deal with survivors of the conflict, and self-care to deal with the trauma generated by being in a conflict zone and covering the events related to it. It is noticeable that it devotes a full chapter on ethical safety decisions, which seeks to help the journalists in deciding whether or not to help those involved in the conflict or to publish the information gathered.

The manual considers legal issues too. It recommends being aware of the regulations applicable to journalists, particularly those related to libel and defamation because they vary greatly from country to country. On this point, it makes specific recommendations to managers and freelancers, like keeping the phone of a local lawyer or knowing labour regulations to obtain the protection given by law.

\subsubsection{The Philippine Journalist Safety Guide-A Handbook for Filipino Journalists}

This safety guide is a training manual published in July 2018 by the National Union of Journalists of the Philippines. It is free to download from the internet, making it accessible to all journalists disregarding employment status and income. The manual is developed in collaboration and partnership with Internews, and is presented as an online self-help resource for journalists who already find themselves in a hazardous situation, or are planning for a dangerous assignment-alternatively also for journalists seeking basic practical knowledge on media safety (National Union of Journalists of the Philippines, 2018, p. 2).

The manual provides "practical tips for Filipino journalists, modified for Philippine coverages and context. It also includes pointers for women, who face two-fold risks and threats when on assignment" (National Union of Journalists of the Philippines, 2018, p. 5). It covers four main aspects: issues before the assignment (Chapter I), issues during the assignment (Chapter II), threats related to the specific topics (Chapter III and IV), digital risks (Chapter V), dealing with trauma and stress (Chapter VI), and legal issues (Chapter VII).

It starts by requesting journalists to make a risk assessment by answering basic questions about the assignment (topic, location, sources), and it provides recommendations on each of the mentioned areas that can be followed by any journalist. It takes into consideration traditional 'hostile environment' threats such as kidnapping and IEDs, but also newer aspects like surveillance, digital attacks and legal harassment. Although there is no specific chapter on gender or other personal characteristics, it does make specific recommendations for women and asks the journalist to consider "age, ethnicity, religious beliefs or nationality and those accompanying you" when making the risk assessment (National Union of Journalists of the Philippines, 2018, p. 8).

\subsubsection{Practical Guideline for the Protection of Journalists: The Venezuelan Manual}

The Civil Society Organization Espacio Público (Public Space) published this manual in 2016 as part of their program to protect journalists in Venezuela. They indicate that the main purpose of the text is to provide journalists with an action plan for cases related to digital and physical safety, and tools to cover social unrest, initiate legal procedures, and to obtain assistance (Espacio Público, 2016, p. 7). Any interested person can download a digital copy from their website, but they also printed it for those who participate in their training.

It is noticeable that they provide a glossary of terms that includes concepts of aggression, attack, threat, censorship, deaths, administrative restrictions, legal restrictions, intimidation, and legal and verbal harassment. This inclusion helps them to establish the baseline of what is considered in the manual and provides journalists with the language needed to refer to the situation that they are facing in an appropriate manner.

The manual does not make specific considerations in terms of gender and ethnicity, but it does consider personal characteristics for the identification of threats. In fact, the guideline starts with the consideration of digital threats, and poses different questions to journalists (i.e., where is data stored, who has access to your digital devices, who knows your password) to facilitate the evaluation of threats and the identification of vulnerabilities, so they can decide which one is more suitable to mitigate risks from a catalogue of tools.

When it comes to personal safety the guideline indicates that journalists are exposed to aggression, impediments to access places, arbitrary confiscation of equipment, destruction of materials, and even retaliation for disseminating information (Espacio Público, 2016, p. 21). However, they do not consider aspects of journalism (the story, assignment, media ethics, etc.) for the identification of threats. The manual only makes a list of recommendations for journalists who cover social protests that includes aspects related to clothing, equipment for physical protection, attitudes toward protesters and security forces, the environment in which the protest will take place, and a list of recommendations for what to do in case of attacks.

Based on the list of situations that journalists can face, the manual considers the Venezuelan legal framework, including constitutional rules and criminal law, and provides different suggestions on how to act in case of the materialization of any of those threats. For example, it advises journalists to request protection measures in case of arbitrary detention (Espacio Público, 2016, p. 29).

\section{Findings from Analysis}

After reviewing the content of each of the course descriptions and safety manuals, we find several differences between those with international focus and those 
with a local focus and consequent narrower target audience. The first one is the availability of information about the content.

The international course descriptions do not provide an extensive explanation of the contents covered during the training, which impedes us from making a detailed comparison of the threats and issues addressed. However, it is possible to affirm that the two international trainers place the emphasis on physical safety. They do not offer much information regarding digital or legal threats and do not clarify how they address risks directly related to gender, ethnicity, and religious or political beliefs. On the contrary, local trainers consider all those elements. Each of the local manuals provides specific information on how journalists must assess personal characteristics to determine the risks and prepare for covering conflict. Their manuals demonstrate that they possess a deep understanding of the context in which they operate, and for that reason, they can offer appropriate tools and advice for journalists who take the training or simply access the local manual for self-study.

It is noteworthy that neither the international course descriptions nor the local manuals are designed to address specific situations. The assessment of risk is limited to hostile environments, but it is not clear what type of environments they are considering. From the available information, we can affirm that international trainers seem to focus on violent and armed conflicts, while local manuals consider periods from peace to social unrest and violent conflicts. For this reason, we can affirm that international training focuses on specific situations for a limited period, and local manuals are meant to be used for any type of assignment and during any situation.

The analysis further indicate that international training courses are similar in content and target audience. In relation to content, they focus on physical and psychological preparation to operate in hostile environments. They simulate hostile environments to teach journalists how to make better decisions under stressful situations, and they provide training on first aid to ensure that journalists know how to act in case of physical injuries. In fact, they even use similar methodologies and highlight the 'real-life' aspect of their training. Because of this content, and from what they advertise on their websites, we can affirm that their target audience is journalists who speak English and have not worked or have limited experience working in hostile environments. It is noticeable that information is available in English, and in the case of AKE International training can be conducted at their centres in the UK, the US, Canada, Australia or Thailand; while the HEAT Training is offered in Norway, Kenya, and Jordan.

Likewise, regional manuals have similar audiences (local journalists) and similar methodologies. The three manuals under analysis use questions to make journalists reflect on their situation, which is also used to make the corresponding risk assessment. The classification of threats and the suggestions given demonstrate that they seek to address the threats that local journalists face. These manuals take special consideration of contextual variation and digital threats. For instance, they provide tips on how to avoid physical aggressions in times of social unrest, like when to use the press emblem, keeping digital data safe by using password-protected devices, and avoiding arbitrary detentions by being aware of the regulations that can and cannot be used against them. It is also noticeable that recommendations related to legal issues tend to be similar. They recommend journalists to know the legal framework that is applicable to them to avoid risks and even add specific references to libel or defamation laws.

The fact that gender is considered in binary terms must be highlighted. Local manuals make specific references to female journalists, but not to LGBTI journalists, while the description of international trainers does not even mention how they address differences between men, women, or LGBTI journalists or staff.

Our sample of training manuals and training content description indicates that they address safety issues faced by local and international journalists; however, the treatment of threats differs greatly between international and local trainers. International trainers emphasize physical safety over digital or legal threats, while local trainers focus on the overall safety of the journalist. Even though they only overlap with the consideration of physical threats, they differ on the content, the focus, the audience, and the methodologies used to train journalists and media staff.

\section{Discussion}

Based on our findings, we argue that local manuals are significantly different in focus and aim, from the content description of the two international training courses considered in this study. The main difference lies in the journalistic processes tied to threats and dangers, such as an assessment of the actors involved in the assignment and the story that is about to unfold. This may be a result of the significant fact that the three manuals from the Philippines, Venezuela, and the Arab region were designed and written by journalists.

Yet, it is noticeable that the only point they have in common is that international course descriptions and (one of the two) local manuals show a lack of consideration of threats related to gender. This is problematic because "women journalists wage a war on two fronts: the war to survive, and the war against the system. They are under pressure to prove themselves, and as a consequence, they may subject themselves to greater danger" (Saady, 2017, p. 7). The Philippine manual pays attention to gender, signifying that these issues truly have surfaced on the ground.

Moreover, as indicated in the sample description section, the fact that the Philippine manual and that the IAWRT manual direct specific concerns at the journalists' individual characteristics, such as gender, ethnicity, na- 
tionality, etc., is very relevant. Although training should emphasise that their safety at work is not mainly their responsibility, journalists would gain from having knowledge about how they may contribute to enhance their personal and professional safety. Personal and professional safety may depart from different institutions but are not inherently split in practical terms; for the individual, the result is usually the same. In the two international course descriptions, the individual's safety appears to be considered from an evaluation of their surroundings, but the personal characteristics of an individual must be accounted for in the context of those surroundings. It is at the personal, practical, and media organisational levels that mitigation can happen, because the journalists themselves cannot easily alter the environment and society.

This is also true for digital safety. As the Venezuelan manual specifies, "in the first place, the responsibility of digital safety falls on users" (Espacio Público, 2016, p. 12). Journalists using digital platforms must know the details needed to improve their digital safety, including aspects related to whom they communicate with and through which internet platform. Journalists must consider the type of digital devices they use, and issues related to connectivity, to better assess where and when they can use them without incurring risks that they are not prepared to mitigate.

Journalists have their own strengths and weaknesses to conduct their work, and each of those capabilities plays an important role in assessing risks. Issues related to the environment in which they are going to work are important because they serve to mitigate risks, but they are not enough. Training manuals and courses need to consider personal aspects (gender, religion, ethnicity, etc.) to provide journalists with the tools they need to remain safe. In addition, as the Philippine manual indicates, "safety protocols and even practices have needed to be adjusted with the constantly changing situation, and why journalists need to constantly review the practices and mechanisms that help them keep safe" (National Union of Journalists of the Philippines, 2018, p. 1).

\section{Conclusion: Context is Too Important to Ignore}

Safety training is designed to teach journalists how to make better decisions in order to remain safe. Yet, we argue that to make them useful for the context in which the journalists are working, it is necessary to consider the type of risks journalists might face in their specific context. The content of local manuals considered in this research demonstrates that threats are complex because they can manifest in the digital and the physical realm and affect a variety of people (i.e., family members, sources, fixers, media). These manuals also suggest that most of the risks faced by journalists are not limited to war zones; on the contrary, they occur in non-armed conflict situations.

Nevertheless, safety training for international journalists travelling across the world to report is largely influ- enced by so-called hostile environment training, often including first aid and field exercises in hostage-taking and training in recognizing weapons and IEDs. While this is still relevant for any person considering entering a conflict zone, we argue that journalist safety relies heavily on understanding the dangers that may appear, for example, during an investigative project or periods of social unrest. There are several reasons to reconsider the foundations on which such training is developed and performed. Perhaps local and international safety training for journalists can gain from including perspectives of each other. Journalism is embedded into the process of globalisation, and cross-national projects revealing, for example, international corporate exploitation and corruption could gain from understanding both geographical and cultural variations and story-related aspects of safety.

For that reason, and in accordance to our findings, we argue that training should take into consideration local contexts (such as regime type, state cohesiveness, and social institutions), globalization, technological advancement, legal issues, and differences in journalistic practices, ethics, and media organizational routines.

Being prepared to assess and manage the environment is surely helpful to remain safe in a 'hostile environment.' However, unlike soldiers, journalists are deployed to engage with people in that environment as their sources and a military or any other non-journalistic approach to a hostile environment can compromise the journalistic task of reporting social injustice. Moreover, journalists have to negotiate both for access to information and for their own protection as they acquire that information. Thus, safety is something that can be trained through a (journalistic) practice focus. The journalist is central to journalist safety. Ethics training and proper organizational routines and investment are additionally important to enhance their safety. While journalists and editors are limited in altering societal challenges due to political restraint, economic imperatives, and market demands, they may influence individual capacities, practices and organizational routines. We argue that this capacity, in the case of journalism, lays closer to the journalistic practice than the 'hostile environment' they are set to navigate and that the media industry therefore may contribute significantly in training their own staff as opposed to, or in addition to, hiring expertise from outside the profession.

\section{Conflict of Interests}

Dr. Marte Høiby is currently a board member of the Norwegian chapter of the International Association for Women in Radio and Television (IAWRT). The authors declare no further conflict of interests.

\section{References}

AKE International. (2017). Journalism in hostile regions. London: AKE International. Retrieved from https:// 
akegroup.com/wp-content/uploads/2017/06/AKESpecial-Report-Journalism-in-Hostile-Regions.pdf

AKE International. (2019). Training. AKE International. Retrieved from https://akegroup.com/training

Barkawi, T., Dandeker, C., Wells-Petry, M., \& Kier, E. (1999). Rights and fights: Sexual orientation and military effectiveness. International Security, 24(1), 181-201.

Chen, G. M., Pain, P., Chen, V. Y., Mekelburg, M., Springer, N., \& Troger, F. (2018). 'You really have to have a thick skin': A cross-cultural perspective on how online harassment influences female journalists. Journalism. Advance online publication. https://doi. org/10.1177/1464884918768500

Committee to Protect Journalists. (2019). Explore CPJ's database of attacks on the press. Retrieved from https://cpj.org/data/killed/?status=Killed\&motive Confirmed\%5B\%5D=Confirmed\&type\%5B\%5D= Journalist\&start_year=1992\&end_year=2019 \&group_by=year

Espacio Público. (2016). Programa de protección para periodistas: Guía práctica [Practical guideline for the protection of journalists]. Caracas: Espacio Público.

Garrido V., M. (2017a). Journalists not spies: The importance of the legal distinction for the protection of journalists during armed conflicts. Journalism Education, 6(2), 48-55.

Garrido V., M. (2017b). The protection of citizen journalists during armed conflicts. In U. P. Carlsson (Ed.), The assault of journalism (pp. 267-278). Gothenburg: Nordicom.

Garrido V., M. (2017c). The right to freedom of expression in the digital era: Limitations v. protection in the case of Venezuelan citizen journalists. San Jose: University for Peace.

Garrido V., M., Høiby, M., \& Mitra, S. (2019). Mediumspecific threats for journalists: Examples from Philippines, Afghanistan and Venezuela. Journalism Practice. Advance online publication. https://doi.org/ 10.1080/17512786.2019.1696697

Henrichsen, J. R., Betz, M., \& Lisosky, J. (2015). Building digital safety for journalism: A survey for selected issues. Paris: UNESCO.

Høiby, M. (2016). Sexual violence against journalists in conflict zones. gendered practices and cultures in the newsroom. In B. von der Lippe \& R. Ottosen (Eds.), Gendering war and peace reporting some insights: Some missing links. Gothenburg: Nordicom.

Høiby, M. (2019a). Covering Mindanao: The safety of local vs. non-local journalists in the field. Journalism Practice, 14(1), 67-83, https://doi.org/10.1080/ 17512786.2019.1598884

Høiby, M. (2019b). Journalism under pressure: A crossnational study of antipress violence and journalist safety (Unpublished Doctoral dissertation). Oslo Metropolitan University, Oslo, Norway.

Høiby, M. \& Ottosen, R. (Eds.). (2015). Journalism under pressure: A mapping of editorial policies for journalists covering conflict. Oslo: Oslo and Akershus University College.

Høiby, M., \& Ottosen, R. (2016). Reduced security for journalists and less reporting from the frontline. In $\mathrm{U}$. Carlsson (Ed.), Freedom of expression and media in transition: Studies and reflections in the digital age (pp. 183-191). Gothenburg: Nordicom.

Høiby, M., \& Ottosen, R. (2018). Journalism under pressure in conflict zones: A study of journalists and editors in seven countries. Media, War \& Conflict, 12(1), 69-86. https://doi.org/10.1177/1750635217728092

MacKinnon, R., Hickok, E., Bar, A., \& Lim, H.-I. (2014). Fostering freedom online: The role of internet intermediaries. Paris: UNESCO.

National Union of Journalists of the Philippines. (2018). Philippine journalist safety guide. Quezon City: National Union of Journalists of the Philippines. Retrieved from https://nujp.org/wp-content/uploads/ 2018/09/NUJPSafety-guide-final1.1-forupload.pdf

Norwegian Refugee Council. (2019). HEAT training. Norwegian Refugee Council. Retrieved from https:// www.nrc.no/heat-training

Rentschler, C. (2007). Risky assignments. Feminist Media Studies, 7(3), 257-279, https://doi.org/10.1080/ 14680770701477875

Saady, A. (2017). What if...? Safety handbook for women journalists. Retrieved from https://www.iawrt.org/ sites/default/files/field/pdf/2017/11/IAWRT\% 20Safety\%20Manual.Download.10112017.pdf

Slaughter, A., Newman, E., Brummel, B., \& Drevo, S. (2018). Journalist safety trainings: Effective for all? Australian Journalism Review, 40(2), 53-65.

UNESCO. (2018). World trends in freedom of expression and media development: Global report 2017/2018. Paris: UNESCO.

United Nations General Assembly. (2012). Report of the special rapporteur on the promotion and protection of the right to freedom of opinion and expression, Frank La Rue. Brussels: United Nations.

\section{About the Authors}

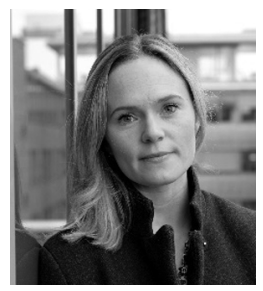

Marte Høiby (PhD) is an Assistant Professor at the Department of journalism and media studies, Oslo Metropolitan University. Her teaching and research interests are within journalism and globalisation, gender, conflict reporting, threats to journalists, and field security. In parallel with her academic work, $\mathrm{H} \varnothing \mathrm{iby}$ has given workshops and safety trainings to journalists and students in Europe, Latin America, Asia, and Africa. 


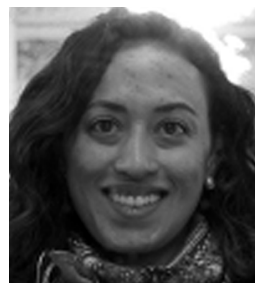

Mariateresa Garrido V. (PhD) is an Assistant Professor and the Doctoral Programme Coordinator at the University for Peace. She is a Venezuelan Lawyer specialized in International Law and Human Rights, and her main research area is related to the exercise of the right to freedom of expression in the digital era and the protection of journalists in Venezuela and Latin America. 